\title{
RECUPERAÇÃO DE METAIS VALIOSOS DE BATERIAS DE NiMH POR PROCESSOS DE SEPARAÇÃO MECÂNICA
}

\author{
D. F. SCHLEMMER ${ }^{1}$, E. TANABE ${ }^{1}$, D. BERTUOL ${ }^{1}$ \\ ${ }^{1}$ Universidade Federal de Santa Maria, Departamento de Engenharia Química \\ E-mail para contato: dfschlemmer@gmail.com
}

\begin{abstract}
RESUMO - A necessidade de desenvolver baterias de alta densidade de energia trouxe para o mercado as baterias de $\mathrm{NiMH}$, utilizadas em diversos aparelhos portáteis e carros elétricos. Essa demanda gerou a necessidade do desenvolverimento de uma rota de processamento para o destino final adequado para as baterias esgotadas. As baterias de $\mathrm{NiMH}$ presentes no estudo provém de telefones celulares danificados ou obsoletos. Inicialmente as baterias foram cominuídas em um moinho de martelos. Em seguida a amostra foi submetida à peneiras vibratórias para que o pó, que se desprende facilmente, fosse separado. Posteriormente, a amostra restante foi enviada a um leito de jorro onde as três principais frações: metais, polímeros e o pó foram separados. Esse processamento propiciou uma eficiente separação dos diferentes componentes presentes nas baterias $\mathrm{NiMH}$.
\end{abstract}

\section{INTRODUÇÃO}

Nas últimas décadas, o crescente aumento do uso de aparelhos portáteis levou ao desenvolvimento de uma quantidade enorme de diversos tipos de baterias. Como consequência, devido a baixa vida útil dessas, se obteve a geração de grande quantidade de baterias esgotadas [1]. No Brasil, foram vendidos 67,8 milhões de telefones celulares em 2013[2]. E esse número é representativo do aumento das vendas de todos os eletroeletrônicos e tende a ser maior em 2014.

Dentre essas baterias encontradas no mercado estão as beaterias de níquel metal hidreto (NiMH). As baterias de níquel metal hidreto são, popularmente, conhecidas como sucessoras das bateria de níquel cádmio, que apesar de terem evoluído significativamente em termos de funcionalidades, sempre tiveram seu nome atrelados aos problemas ambientais causados pelo cádmio. E nesse sentido, as baterias de NiMH são ecologicamente mais corretas, uma vez que não possuem metais pesados ou tóxicos em sua composição [3]. As características funcionais das baterias de níquel metal hidreto são muito similares às de Níquel-Cadmio. Sua principal diferença consiste no uso do hidrogenio adsorvido em uma liga de hidreto metálico (MH)[4]. Exemplos de 
M são ligas $\mathrm{AB}_{2}$ que pode ser uma liga de $\mathrm{TiNi}_{2}$, e $\mathrm{AB}_{5}$ que pode ser uma liga de $\mathrm{LaNi}_{5}$. E por uma razão de economia, o La é substituído por terras-raras. [5]

Ao final da sua vida útil, as baterias NiMH tornam-se um grande problema [6], e nesse momento surge outra necessidade: Desenvolver métodos de reciclagem e um destino final adequado para estas baterias. Diante deste contexto, o objetivo deste trabalho foi desenvolver um processamento mecânico que possibilitae a separação das três frações principais encontradas nas baterias de NIMH: metais, polímeros e pó (contituintes do cátodo e anodo). Essas frações separadas, posteriormente podem passar por outros processos, a fim de serem reutilizados em outras indústrias.

\section{MATERIAIS E MÉTODOS}

\subsection{Caracterização dos componentes das baterias}

As baterias de NiMH presentes no estudo provém de telefones celulares da marca danificados ou obsoletos. Foram selecionadas, ao acaso, seis baterias recarregáveis de niquel metal hidreto, nas quais todas apresentavam acumuladores prismáticos. Os acumuladores prismáticos são constituídos por um invólucro externo de aço, um eletrodo positivo, um eletrodo negativo e pelos separadores. O eletrodo negativo é constituído por uma placa simetricamente perfurada e coberta por uma pasta preta. $\mathrm{O}$ eletrodo positivo é uma tela de metal fina também impregnado por uma pasta escura.

\subsection{Processos de separação dos materiais}

Inicialmente os componentes das baterias foram separados manualmente e classificados individualmente conforme a sua percentagem mássica. Em seguida as amostras de baterias foram cominuídas em um moinho de martelos no qual foi utilizada uma peneira de $1 \mathrm{~mm}$ de abertura. Dessa amostra parte do pó presentes nas baterias foi retirada através das peneiras vibratórias devido ao fácil desprendimento em relação aos outros componentes da bateria. O restante do material foi enviado à um leito de jorro para que fosse separado as demais frações de interesse: os metais, os polímeros e o restante do pó que está aderido ao polímero.

Na primeira etapa do processo no leito de jorro foi separado os metais através da elutriação do polímero e do pó, devido as diferenças de tamanho e de massas específicas dos materiais. Como o metal apresenta uma maior massa específica em relação aos demais produtos, o mesmo ficou retido no fundo do leito de jorro. O polímero e o pó separados na $1^{\circ}$ etapa foram levados novamente para o leito de jorro, no qual a separação do pó aderido no polímero exigiu a inserção de uma tela que permite somente a passagem do pó, sendo o polímero ficou retido dentro do leito. Na Figura 1 está ilustrado um fluxograma com a sequência de operações realizadas na separação dos diferentes materiais. 


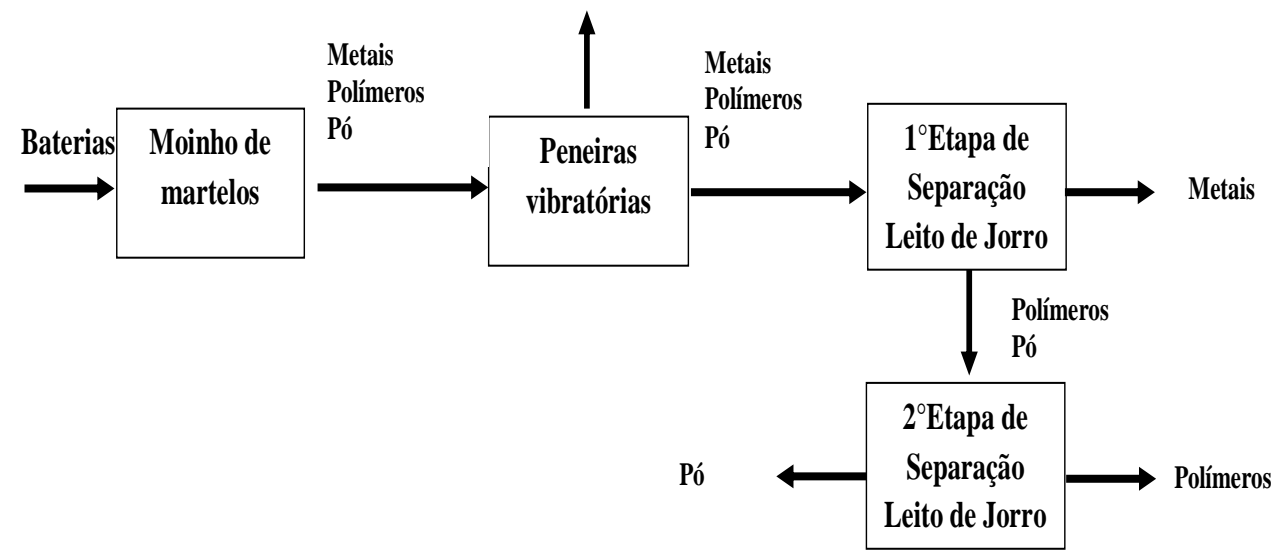

Figura 1 - Fluxograma do processo de produção.

\section{RESULTADOS E DISCUSSÕES}

\section{1 .Caracterização dos componentes da bateria}

Os componentes das baterias foram manualmente separados e classificados como apresentado na Tabela 1. A caracterização mostrou que quase $90 \%$ da massa das baterias é constituida pelos materiais que compoem os acumuladores prismáticos e que cerca de $56 \%$ da massa total é constituida pelos eletrodos positivos e negativos.

Tabela 1: Caracterização das bateriais NiMH.

\begin{tabular}{|c|c|c|c|c|c|c|}
\hline \multirow{3}{*}{$\begin{array}{c}\text { BATERIA } \\
\begin{array}{c}\text { Massa Inicial } \\
\text { (g) }\end{array} \\
\text { Componentes }\end{array}$} & \multicolumn{2}{|c|}{1} & \multicolumn{2}{|c|}{2} & \multicolumn{2}{|c|}{3} \\
\hline & \multicolumn{2}{|c|}{52.87} & \multicolumn{2}{|c|}{52.71} & \multicolumn{2}{|c|}{52.83} \\
\hline & $\operatorname{Massa}(\mathrm{g})$ & \%Mássica & $\operatorname{Massa}(\mathrm{g})$ & \%Mássica & $\operatorname{Massa}(\mathrm{g})$ & \%Mássica \\
\hline Polímeros & 3.84 & 7.27 & 3.77 & 7.15 & 3.86 & 7.31 \\
\hline Placa (circuito) & 0.27 & 0.52 & 0.26 & 0.50 & 0.28 & 0.53 \\
\hline $\begin{array}{c}\text { Fração } \\
\text { metálica }\end{array}$ & 0.51 & 0.97 & 0.52 & 0.99 & 0.51 & 0.97 \\
\hline $\begin{array}{l}\text { Placas de Ni } \\
\text { Perfuradas* }\end{array}$ & 2.12 & 4.01 & 1.96 & 3.73 & 2.03 & 3.85 \\
\hline Polímeros* & 0.40 & 0.77 & 0.39 & 0.75 & 0.40 & 0.76 \\
\hline $\begin{array}{c}\text { Invólucro } \\
\text { externo de aço* }\end{array}$ & 14.13 & 26.72 & 13.82 & 26.22 & 14.13 & 26.74 \\
\hline Separador* & 1.20 & 2.27 & 1.07 & 2.04 & 1.15 & 2.19 \\
\hline $\begin{array}{l}\text { Eletrodo } \\
\text { Positivo* }\end{array}$ & 16.29 & 30.82 & 15.89 & 30.15 & 16.19 & 30.66 \\
\hline $\begin{array}{l}\text { Eletrodo } \\
\text { Negativo* }\end{array}$ & 13.07 & 24.72 & 13.67 & 25.93 & 13.37 & 25.31 \\
\hline
\end{tabular}




\begin{tabular}{|c|c|c|c|c|c|c|}
\hline BATERIA & \multicolumn{2}{|c|}{4} & \multicolumn{2}{|c|}{5} & \multicolumn{2}{|c|}{6} \\
\hline Massa & \multicolumn{2}{|c|}{53.23} & \multicolumn{2}{|c|}{53.20} & \multicolumn{2}{|c|}{52.74} \\
\hline Componentes & $\operatorname{Massa}(g)$ & \%Mássica & $\operatorname{Massa}(g)$ & \%Mássica & $\operatorname{Massa}(g)$ & \%Mássica \\
\hline Polímeros & 3.85 & 7.23 & 4.13 & 7.77 & 3.79 & 7.20 \\
\hline Placa (circuito) & 0.25 & 0.47 & 0.27 & 0.50 & 0.26 & 0.49 \\
\hline $\begin{array}{c}\text { Fração } \\
\text { metálica }\end{array}$ & 0.58 & 1.09 & 0.54 & 1.02 & 0.54 & 1.03 \\
\hline $\begin{array}{l}\text { Placas de Ni } \\
\text { Perfuradas* }\end{array}$ & 2.07 & 3.89 & 2.45 & 4.61 & 2.04 & 3.88 \\
\hline Polímeros* & 0.404 & 0.76 & 0.36 & 0.68 & 0.39 & 0.75 \\
\hline $\begin{array}{c}\text { Invólucro } \\
\text { externo de aço* }\end{array}$ & 13.98 & 26.26 & 13.93 & 26.18 & 14.01 & 26.57 \\
\hline Separador* & 1.15 & 2.17 & 1.05 & 1.98 & 1.20 & 2.29 \\
\hline $\begin{array}{l}\text { Eletrodo } \\
\text { Positivo* }\end{array}$ & 16.12 & 30.28 & 15.27 & 28.71 & 15.74 & 29.84 \\
\hline $\begin{array}{c}\text { Eletrodo } \\
\text { Negativo* }\end{array}$ & 13.76 & 25.85 & 13.33 & 25.06 & 13.31 & 25.23 \\
\hline
\end{tabular}

*Componentes dos acumuladores

Na Figura 2 é apresentada a fração massica média dos componentes para as seis baterias.

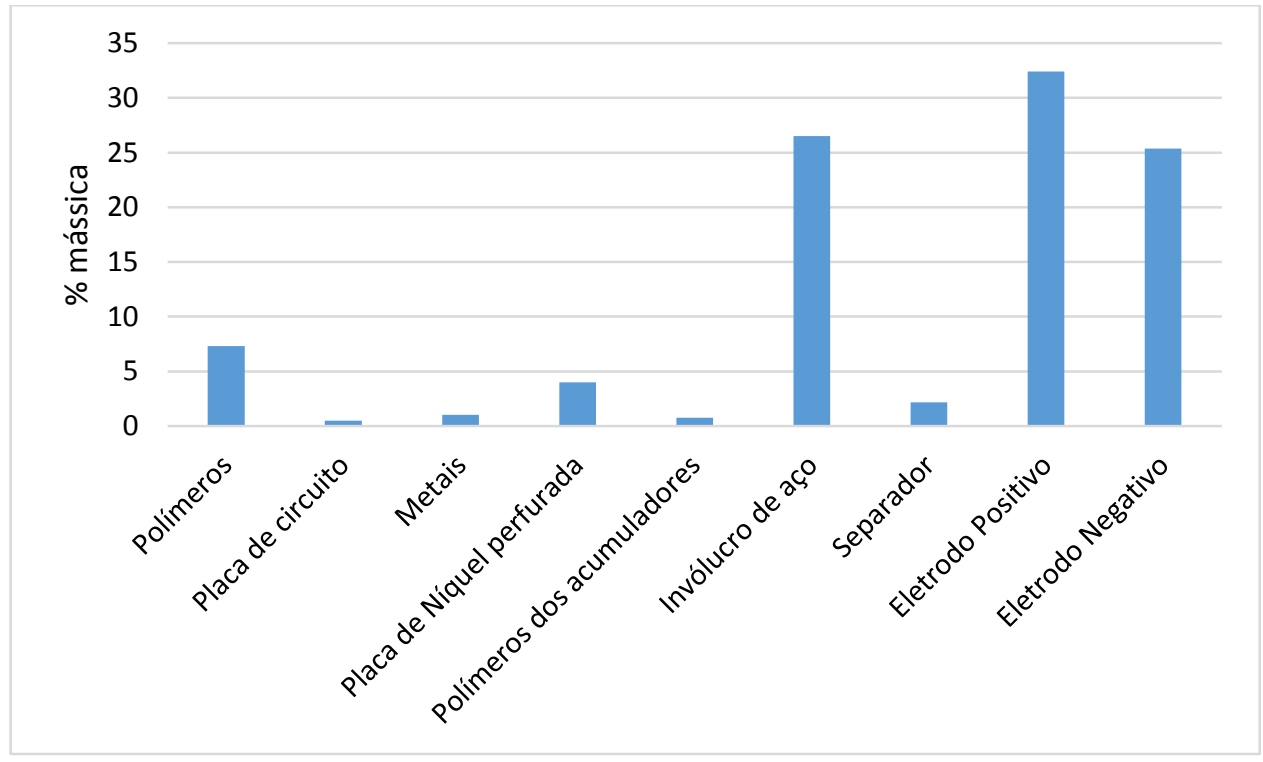

Figura 2 - Fração média de cada componente

\subsection{Processos Mecânicos de Separação}

A massa inicial de 08 baterias foi de 400,6 g e este material foi enviado para a comunuição em um moinho de martelos, onde houve uma perda de 5,6\%. Após a moagem, esse material foi 
peneirado com malha 65 Ty $(0,212 \mathrm{~mm})$ para que fosse removido parte do pó mais fino. Nessa etapa do processo conseguiu-se remover cerca de $93,47 \mathrm{~g}$ de material particulado, sendo o restante do material enviado ao leito de jorro para separação dos demais componentes da bateria.

Na primeira etapa de separação no leito de jorro como os metais apresentam uma massa específica mais elevada em relação aos polímero e ao pó, o mesmo permaneceu na parte inferior do cone do leito e o restante foi enviado à um coletor do tipo ciclone através do transporte pneumático. Obteve-se, então, duas frações: 99,05 g de metais e 187,83g, referentes ao polímeros e o pó, no coletor.

O metais retidos no equipamento foram guardados e o material arrastado no coletor foi novamente alimentado ao leito de jorro com o intuito de separar o pó aderido nos polímeros e principalmente no tecido sintético que constitui o separador. Nessa etapa, devido a pequena diferença de massa específica entre os contituintes da amostra não foi possível separá-los usando apenas a variação de velocidade. Foi necessário adaptar uma tela específica na saída do leito para que os polímeros e o pano sintético ficassem retidos dentro do mesmo e o pó fosse separado no coletor. Nesta segunda etapa foram separados aproximadamente 74,76 g de pó no coletor.

Na Figura 3 é apresentado o fluxograma com o balanço de massa descrito acima.



Figura 3 - Balanço de massa para o processo de separação 


\subsection{Caracterização dos materiais separados}

Os materiais separados no processamento mecânico foram caracterizados conforme mostrado na Tabela 2. Foram determinados os diâmetros das partículas $\left(\mathrm{d}_{\mathrm{p}}\right)$ através de 2 métodos; difração a laser e peneiramento. A determinação da massa específica dos materiais separados foi realizada por meio de um picnômetro de gás hélio.

Tabela 2: Caracterização dos materiais separados.

\begin{tabular}{ccc}
\hline Material & $\rho\left(\mathbf{g} / \mathbf{c m}^{\mathbf{3}}\right)$ & $\mathbf{d}_{\mathbf{p}}(\mathbf{m m})$ \\
\hline Pó & 4.15 & $0.07^{(\mathbf{1})}$ \\
\hline Metais & 7.00 & $3.30^{(2)}$ \\
\hline Polímeros & 2.27 & $2.60^{(2)}$ \\
\hline
\end{tabular}

(1) Difração a laser; (2) Peneiramento

\subsection{Velocidades de arraste do material}

Nas etapas de separação dos materiais (Etapa 1 e Etapa 2) utilizando o leito de jorro, foram coletados os valores da velocidade do gás no leito $\left(\mathrm{V}_{\mathrm{f}}\right)$ em função da queda de pressão $(\Delta \mathrm{P})$ causado pela presença do material, conforme apresentado na Tabela (3). O valor de $\left(\mathrm{V}_{\mathrm{f}}\right)$ foi tomado como sendo o valor no bocal de entrada do cone do leito.

Tabela 3: Valores experimentais da velocidade do gás no leito e queda de pressão no leito de jorro.

\begin{tabular}{cccc}
\hline \multicolumn{2}{c}{ Etapa (1) } & \multicolumn{2}{c}{ Etapa (2) } \\
\hline $\mathbf{V}_{\mathbf{f}}(\mathbf{m} / \mathbf{s})$ & $\Delta \mathbf{P}\left(\mathbf{m m H}_{\mathbf{2}} \mathbf{O}\right)$ & $\mathbf{V}_{\mathbf{f}}(\mathbf{m} / \mathbf{s})$ & $\Delta \mathbf{P}\left(\mathbf{m m} \mathbf{H}_{\mathbf{2}} \mathbf{O}\right)$ \\
\hline $\mathbf{1 . 5}$ & 2.0 & 2.5 & 1.0 \\
\hline $\mathbf{1 . 8}$ & 3.0 & 4.0 & 1.0 \\
\hline $\mathbf{2 . 5}$ & 3.5 & 5.2 & 2.0 \\
\hline $\mathbf{3 . 8}$ & 4.0 & 6.0 & 3.0 \\
\hline $\mathbf{5 . 0}$ & 4.3 & $\mathbf{8 . 0}$ & $\mathbf{4 . 0}$ \\
\hline $\mathbf{6 . 3}$ & $\mathbf{4 . 0}$ & 9.3 & 3.0 \\
\hline $\mathbf{7 . 6}$ & 5.0 & 11.5 & 4.0 \\
\hline $\mathbf{1 3 . 8}$ & 8.0 & 14.6 & 7.0 \\
\hline
\end{tabular}


A análise da Tabela 5 mostra os valores das velocidades do gás marcados em negrito, no qual representam as velocidades de início das separações dos materiais. Na Etapa (1) do processo o principal objetivo era primeiramente separar os metais dos polímeros e do pó. Para isto observase que a velocidade do leito aplicada para o início da separação dos metais e polímeros foi de 6,3 $\mathrm{m} / \mathrm{s}$. Para esta velocidade apenas os materiais menos denso no leito (pó e polímero) começaram a ser arrastados para o coletor. Como o metal apresenta uma massa específica maior em relação aos outros materiais logo necessita de uma velocidade terminal das partículas maior em relação aos demais materiais, e desta forma o mesmo ficou retido no leito.

$\mathrm{Na}$ Etapa (2) foram inseridos o pó e os polímeros novamente no leito de jorro para tentar separar estes dois materiais. Como foi dito anteriormente como parte do pó estava aderido ao polímero foi necessário à inserção de uma tela metálica no leito para que apenas as partículas de pó fossem separadas no coletor do tipo ciclone e os polímeros fossem interceptados na tela metálica e retidos no fundo do cone. Conforme a Tabela 5 (Etapa 2) pode observar que o início da velocidade de arraste foi um pouco superior ao da Etapa 1, com velocidade de $8 \mathrm{~m} / \mathrm{s}$. Após a separação dos materiais no leito de jorro, pode se observar que utilizando apenas as operações de processamento mecânico (moagem e peneiração) e um elutriador do tipo jorro, foi possível obter diferentes frações de materiais podendo ser utilizadas diretamente pela indústria de reciclagem ou comercializadas no mercado.

\section{CONCLUSÕES}

Os resultados obtidos mostram que a separação dos materiais de interesse ocorre de forma bem satisfatória, pois se verificou baixo índice de contaminação em cada fração separada.

Os balanços de massa mostram que dos 383,35g dos materiais presentes nas baterias, $168,23 \mathrm{~g}$ foram separados na forma de pó. Isso siginifica que quase $50 \%$ do material foi recolhido na forma de pó. Esse valor está bem próximo da massa do eletrodo positivo e negativo juntos que é em sua maioria pó. Em experimentos realizados a carater de teste onde o pó foi separado apenas por peneiras vibratórias o rendimento máximo foi de apenas $24 \%$, mostrando que o conjunto peneira e leito de jorro apresenta um melhor rendimento, além disso consegue-se separar também os metais e os polímeros eficientemente.

\section{REFERÊNCIAS BIBLIOGRÁFICAS}

1. BERTUOL, D. A.; BERNARDES, A. M.; TENÓRIO, J.A.S. Spent NiMH batteries: characterization and metal recovery through mechanical processing. Journal of Power Sources. , v.160, p.1465 - 1470, 2006.

2. AMBROSIO, R. C., TICIANELLI, E. A. Baterias de NiMH, uma alternativa para as baterias de Níquel Cadmio, Química Nova, V24,2001. 
3. BARBOSA, J. F.; GÇORIA, N. F. A.; GOME.A; Estudo sobre o Impacto de Baterias de Telefone Celular no meio ambiente. Monografia. 1999.

4. FLORIANO, R. Caracterização de Baterias de Níquel Hidreto Metálico e de ĺons Lítio de Telefones Celulares. Londrina, 2009

5. SAX, N.Irving, Dangerous properties of industrial materials. 4.ed. New York: Van Nostrand Reinhold Company. 1975.

6. VARELA, H.; Huguenin, F.; Malta, M.; Torresi, R. M.; Quim. Nova 2002, 25, 287.

7. PETROVICK, J. J. Advanced Concepts for Hydrogen Storage Apresentação DOE Hydrogen Storage Workshop- Argonne National Laboratory, 2002. 